\title{
Tenperatura aldaketak orekatzen dituen ehun adimentsua
}

\author{
(Temperature fluctuations balanced by intelligent textiles)
}

\author{
Amaia Moreno, Antonio Veloso-Fernández* \\ Kimika Fisikoa Saila, Zientzia eta Teknologia Fakultatea FCT/ZTF, \\ Euskal Herriko Unibertsitatea (UPV/EHU)
}

LABURPENA: Material adimenduen presentzia gero eta nabarmenagoa da gaur egun, gehienbat ehungintzan. Material hauen artean poliuretanoak dira ezaugarri onenak aurkezten dituztenak, eta garrantzitsua da hauen trantsizio tenperatura gorputz tenperaturaren parekoa izatea, forma-memoria izaera aktibatzeko; beroa baita aplikatu beharreko kanpo estimuluetariko bat, aplikazio gisa biomedikuntzan edo arropetan erabili ahal izateko. Giza gorputzak berez orekako tenperatura bat dauka eta homeotermoa da, hala ere, naturak eskaintzen dituen mugak gaindi daitezke ehunetan fasez aldatzen diren materialak jarriz gero; modu horretan eramaileak konfort termikoa izanik momentu oro. Lan honetan, material konposatu edo konpositeak aztertuko dira, konkretuki polimeroz eta partikulaz osatuta daudenak; zuntzak edo hariak bilakatuko direnak estrusio prozesuaren bidez, amaieran, aipatutako propietateak eguneroko arropetan eraman ahal izateko.

HITZ GAKOAK: forma-memoriadun polimeroak, poliuretanoak, konpositeak, PCM, ehunak.

ABSTRACT: The presence of smart materials are increasing nowadays, especially in the textiles. Among these materials, polyurethanes have shown the best properties, and their transition temperature should be just like body temperature, to activate shape-memory effect; this is because the heat is one of the external stimuli which must be exposed to, in order to apply in biomedicine and clothing. The human body has a stable temperature, but the limits offered by nature can be exceeded by putting phase change materials in the fabric, so that the person who wears it has thermal comfort. The composite material or composites, which have been made of polymer and particles, are going to be studied in this work. This material has been become fibers through the extrusion technique, so the properties mentioned can be carried in everyday clothes.

KEYWORDS: shape-memory polymers, polyurethanes, composite, PCM, textile.

\footnotetext{
* Harremanetan jartzeko / Corresponding author: Antonio Veloso-Fernández. Kimika Fisikoa Saila, Zientzia eta Teknologia Fakultatea, UPV/EHU Sarriena auzoa, z/g (48940 Leioa). - antonio.veloso@ehu.eus - https://orcid.org/0000-0003-1309-2373

Nola aipatu / How to cite: Moreno, Amaia; Veloso-Fernández, Antonio (2022). «Tenperatura aldaketak orekatzen dituen ehun adimentsua". Ekaia, 42, 2022, 87-106. (https://doi.org/10.1387/ekaia.22929).

Jasotze-data: 2021, ekainak 22; Onartze-data: 2021, urriak 8

ISSN 0214-9001 - elSSN 2444-3255 / (c) 2022 UPV/EHU
}

(c) (i) $(-)$ Lan hau Creative Commons Aitortu-EzKomertziala-LanEratorririkGabe 4.0 Nazioartekoa 


\section{SARRERA}

\subsection{Forma-memoriadun polimeroak}

Polimero hitza grekotik dator, non «poli-» aurrizkiak «asko» esan nahi duen eta «mero» substantiboa «atal» moduan adieraz daitekeen [1]. Definizio orokor bezala; konposatu makromolekular bat da, sintetikoa edo naturala, polimerizazio bidez eratzen dena; hau da, unitate estrukturalen errepikapenak edo lotura kobalente bidezko monomeroen elkarketa. Bi polimerizazio mota bereizten dira: adizio bidezkoa edo kondentsazio bidezkoa. Lehenengoaren kasuan, monomeroa katera lotzean ez da azpiprodukturik sortzen. Bigarrenean bai, atomoen galera gertatzen da; orokorrean ur molekulak [2].

Gaur egun, hainbat polimero existitzen dira eta irizpide desberdinengatik sailkatzen dira. Jatorriaren arabera: naturalak (azido desoxirribonukleikoa (DNA), kitina, proteinak) edo sintetikoak (poliester, nylon, polibinil kloruroa (PVC)). Monomero kopuruaren arabera (homopolimeroak edo kopolimeroak) edota propietateen arabera; non tenperaturarekiko portaera desberdinak aurkezten dituzten. Sailkatzeko modu bat 1. irudian erakusten da. Termoplastikoak, orokorrean, pisu molekular altuko polimeroak dira, non polimero kateak interakzio fisikoz (Van der Waals loturak, hidrogeno zubiko loturak, dipolo-dipolo elkarrekintzak...) eratutako domeinuak erakusten dituzten. Tenperatura handitzean, plastikoak edo deformagarriak izatetik, egoera jariakor batera eraldatzen dira, lotura intermolekularrak desegiten baitira; modu horretan zenbait propietate fisiko eraldatzen direlarik. Berriz hoztean, beste material bat bilaka edo birzikla daitezke. Termoegonkorrak, sare moduan lotuta dauden polimero zurrunak dira, urtuezinak eta disolbaezinak direnak. Beraz, tenperatura handitzean interakzio fisikoz zein lotura kobalentez eratutako domeinuak txikitzen dira, degradazioarekiko erresistentzia handituz. Aurrekoekin alderatuz, tenperatura oso altuetan degrada daitezke. Azkenik, elastomeroak, polimero amorfoak dira eta portaera elastikoa aurkezten dute. Tenperatura handitzean deformatzen dira, baina kasu honetan lotura kobalenteen presentzia dela eta, hasierako forma berreskura daiteke aplikatutako estimulua kentzerakoan $[2,3]$.

a)

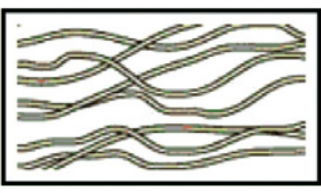

b)

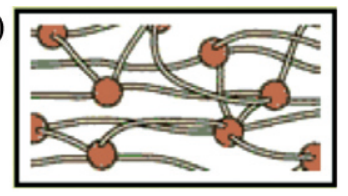

c)

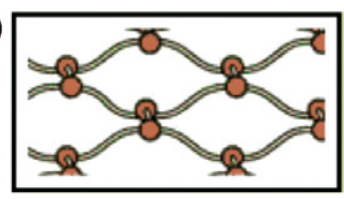

1. irudia. Polimero motak: a) termoplastikoa, b) termoegonkorra eta c) elastomeroa [4]. 
Azken sailkapen honetan oinarrituz, forma-memoriadun materialak (Shape-Memory Materials, SMM) defini daitezke; hau da, forma iraunkor batetik abiatuz, desitxura daitekeena eta aldi baterako egonkor mantendu. Denboraldi hau amaitzen da materialak estimulu egokia jasotzen duenean, hasierako itxura berreskuratuz. Estimuluen artean honako hauek bereizten dira: eremu magnetikoa, elektrikoa, $\mathrm{pH}$ aldaketa, argia eta tenperatura; azken hori erabiliena izanik [5]. Beraz, forma-memoriadun izaera egituraren menpekoa da, eta polimero batean, makroegitura iraunkorra eta aldakorra kontsideratzen den bitartean, mikroegituran lotura fisiko zein kimikoak egon behar dira materialak desplazamendua edota apurketa saihestu ahal izateko, inolako estimulurik jasotzen ez duen bitartean. Lotura hauek dira egonkortasuna ematen dutenak eta aldi berean hasierako egoerara bueltatzeko aukera ahalbidetzen dutenak. Modu horretan, forma-memoriadun polimeroak (Shape-Memory Polymers, SMP) definitzen dira. Haien abantailen artean hauexek daude: elastikotasuna, dentsitate baxua $\left(1-1,3 \mathrm{~g} / \mathrm{cm}^{3}\right)$ [3], merkeak izatea eta biobateragarri zein biodegradagarri izateko aukera eskaintzea.

Forma-memoria edukitzeko, beharrezkoa da materialek trantsizio-termiko itzulgarria (trantsizio-tenperatura, $\mathrm{T}_{\text {trans }}$ ) edukitzea, modu horretan denboraldiko forma finka daiteke; hau da, egonkortasuna berma daiteke domeinu edo mikrofaseen ondorioz; eta beste aldetik, berezko egoerara bueltatzeko indar elastikoa indargabetu $\mathrm{T}_{\text {trans }}$ gaindituz gero. Polimeroaren kristalinitate-mailaren arabera, beirazko trantsizio-tenperatura $\left(\mathrm{T}_{\mathrm{g}}\right)$ edo fusio-tenperatura $\left(\mathrm{T}_{\mathrm{f}}\right)$ kontsidera daiteke [4]. Beraz, forma-memoria efektuan bi pauso bereiziko dira (2. irudia): «programazioa» eta «berreskurapena», zeinak tenperaturaren menpe egongo baitira [3].

Termikoki estimulatutako polimero erdikristalino baten joera aztertuko da 2. irudian. Memoria-efektua kuantifikatzeko ziklo mota hauek erabiltzen dira. Lehendabizi, polimeroaren forma iraunkorretik hasita, $\mathrm{T}_{\text {trans }}$ - $\mathrm{tik}$ gora berotzen eta deformatzen da; jarraian hozten delarik deformazio hori mantenduz. Hau da, denboraldiko forma lortzen da. Egituran, tenperatura jaistean $\mathrm{T}_{\text {trans }}$-tik behera, domeinu erdikristalinoak edo beiraztatuak eratzen dira katean, zeintzuek deformazio egoerarekin elkartze puntuak osatzen dituzten; denboraldiko forma egonkor mantenduz. Polimeroa berriz berotzean ( $T_{\text {trans }}$ gainetik), aipatutako domeinuak desagertzen dira eta memoria-efektuaren eragile izanik, jatorrizko forma berreskuratzen da. 


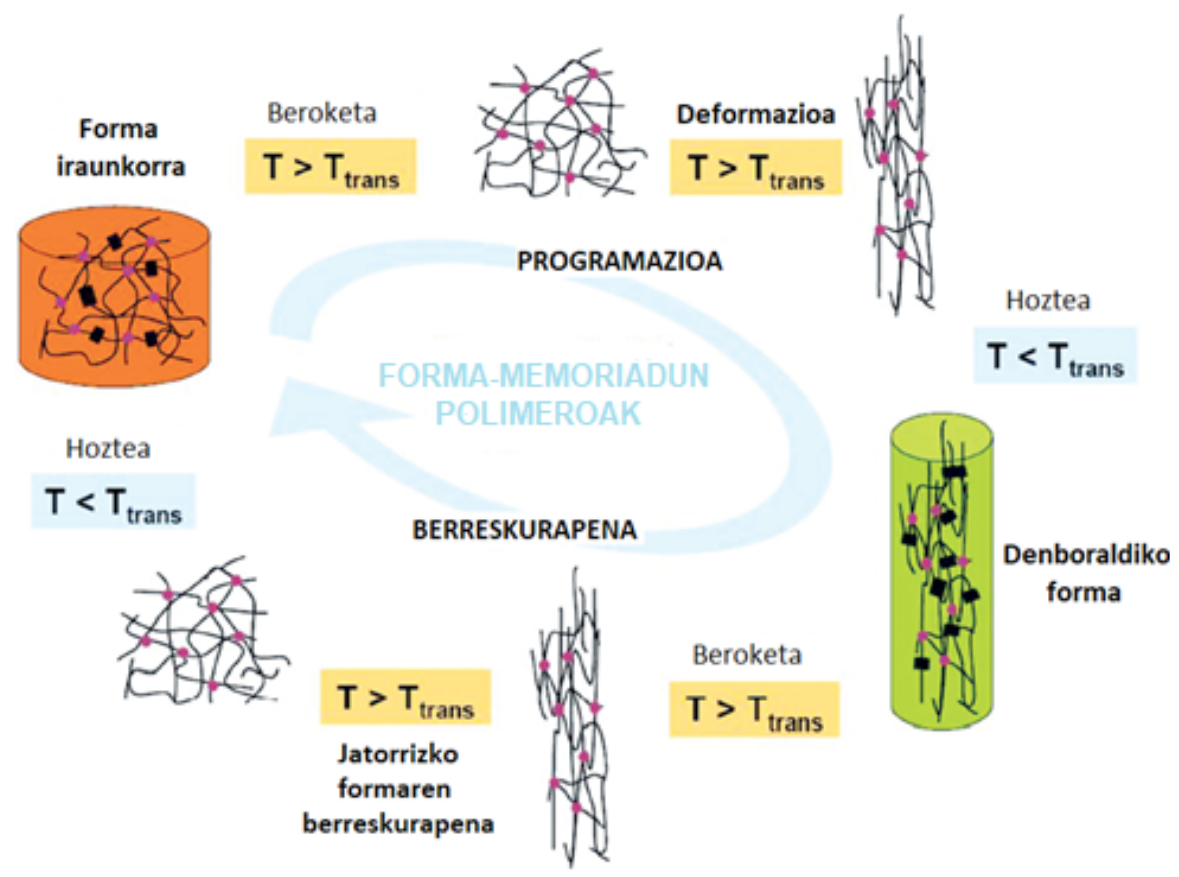

2. irudia. Polimero erdikristalino baten forma-memoria efektuaren irudi eskematikoa [4].

Mikroegitura eta natura kimikoaren arabera, SMP mota ugari aurki daitezke. Forma-memoria aurkezten duten materialen artean, poliuretanoek (PU) propietate fisiko eta mekaniko hoberenak azaldu dituzte. Forma-memoriadun poliuretanoen (SMPU) egitura kimikoari dagokionez, bi segmentu bereizten dira: segmentu gogorra (SG), forma iraunkorraren erantzulea eta bi osagaien ondorioa, diisozianatoa eta kate hedatzailea; eta segmentu biguna (SB), poliol taldeak osatuta eta denboraldiko formaren arduraduna dena [3]. SG, kristalinoa edo erdikristalinoa izan daiteke. Orokorrean, trantsizio-tenperatura altuak izaten ditu, hidrogeno-lotura eta dipolo-dipolo elkarrekintzak direla medio. Diisozianato (-NCO taldea) eta kate hedatzailearen (-OH taldea) artean pisu molekular handiko PUa eraikitzen dute poliadizio bidez, uretano funtzio taldea honako hau izanik: -NH-CO-O-. SBren domeinu amorfo edo erdikristalinoa, polieter edo poliester glikolak osatzen dute; eta mota eta luzeraren arabera, PUaren propietate fisikoak alda daitezke. 3. irudian, domeinu zurrunak eta malguak ondo desberdindu daitezke, biak batera PUaren egitura osatuz $[6,7]$. 

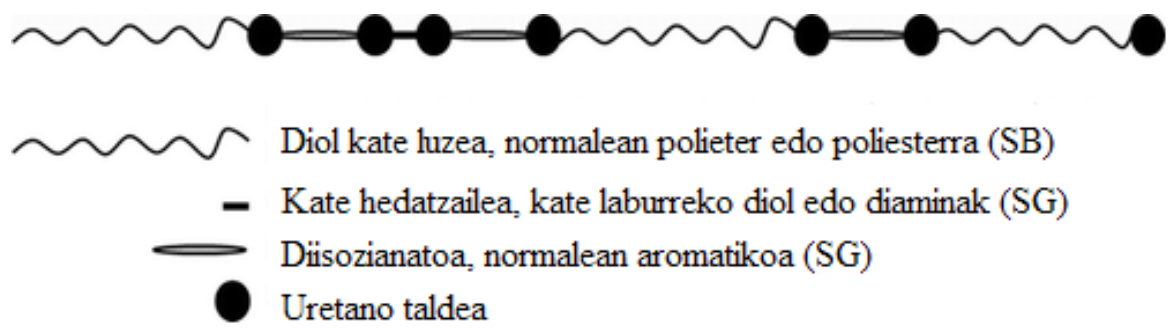

3. irudia. SMPUen irudi eskematikoa eta segmentu bakoitzaren osagaiak [8].

\subsection{Material konpositeak}

Material konposatuak edo konpositeak, propietate fisiko-kimiko desberdinak dituzten bi material edo gehiagoren nahasteak dira, eta sortutako material berriaren propietateak indibidualki eskaintzen dituztenak baino hobeagoak izan ohi dira. Hala ere, egituran bi konposatuak ez dira elkarren artean disolbatzen, ezta nahasten ere. Hori dela eta, fisikoki ezberdindu eta mekanikoki bereiz daitezke [9].

Konposite naturalak existitzen dira; egurra adibidez, zeinak zelulosazko zuntzak beste bi substantzia ahulagoei lotuta dauden: lignina eta hemizelulosa. Hauen konbinazioz, egurra material oso gogorra bilakatzen da. Hala ere, testuinguru honetan artifizialki egindako fase anitzeko materialetan oinarrituko gara. Asko bi fasez osatuta daude, non fase jarraitua edo matrizea eta fase barreiatua bereizten diren. Fase jarraitua, harikorra (ez labila) eta elastikoa izan ohi da eta propietate fisiko-kimikoen erantzulea da. Atal honetan, material zeramikoak, metalikoak eta polimerikoak bereizten dira. Fase barreiatua, aldiz, eragile sendogarria da, baina gehienetan hauskorra ere bai. Hemen, partikulak, zuntzak, xaflak... aurkitzen dira eta tamaina, itxura eta noranzkoa faktore oso garrantzitsuak dira.

Konposatu polimerikoetan oinarrituz, matrizea erretxina edo polimeroa izaten da normalean; termoplastikoa edo termoegonkorra, eta fase barreiatuaren kasuan, beirazko edo karbonozko zuntzak, silize partikulak... Nahaste hauen abantailen artean hauek aurkitzen dira: arintasuna, beira trantsizio tenperatura altuak, erresistentzia altuak eta isolatzaile izaera. Baina desabantailak baditu ere; harikorrak dira, fabrikazio prozesu konplexuen beharra dute hutsuneak edo poro tamainak ahalik eta txikienak izateko; horrek kostua handitzea eragiten duelarik; hala ere, matrize eta errefortzuaren arteko atxikitasun ona eskuratzen da [9].

Matrize polimerikoari fasez aldatzeko gai diren partikulak (Phase Change Materials, PCM) gehitzean, beroa xurgatzeko, biltegiratzeko edo askatzeko gaitasuna daukaten materialak lortuko dira. Halakoak tenpera- 
tura zehatz batean fasez aldatzeko gai dira; hori dela eta, energia termikoaren biltegiratze prozesuetan aplikazio garrantzitsua suposatzen dute. Gaur egun, eraikuntzetan erabiltzen hasi dira, eraikin barneko tenperaturak eroso mantentzeko. Inguruko baldintzak aldatzean, adibidez tenperaturak jaistean, PCMak ordura arte biltegiratu duten energia bero moduan askatuko dute $[10,11]$.

PCM bakoitza tenperatura bat du, non beroa xurgatzen edo askatzen den. Tenperatura hori fusio-tenperatura $\left(T_{f}\right)$ moduan definituko da eta desberdina da PCM bakoitzerako; bi kategoria desberdinetan sailka daitezke: konposatu ez-organikoak eta konposatu organikoak. PCM ez-organikoetan gatzak, gatz hidratatuak, metalak eta hauen aleazioak bereizten dira; PCM organikoetan, berriz, kate linealez osatutako hidrokarburoak, gantz azidoak, polietilenglikola eta n-alkanoak bereizten dira [10].

Mikrokapsulazioa, estaldura, ijezketa eta injekziozko moldaketa dira burutu beharreko zenbait prozesu PCMak egitura bati atxiki baino lehen. Lan hau, mikrokapsulatutako materialetan oinarrituko da. Honen abantaila nagusiak bero transferentzia azalera handiagoan hedatzea eta PCM materialen erreaktibitate maila murriztea izanik. Behin mikrokapsulatuta, matrize polimerikoari erantsi ahal zaio; 4a. irudian PCMak zuntzekin batera nahastuta ikusten dira, estrusio-prozesuaren bitartez lortu dena, gero ehun bilaka daitekeena (4b. irudia) [11]. Modu horretan, ehungintzarako abantaila handia suposatzen du, honen helburua baita material adimentsuen bero-ahalmena handitzea eta aplikazio zehatzetarako erabiltzea.

a)

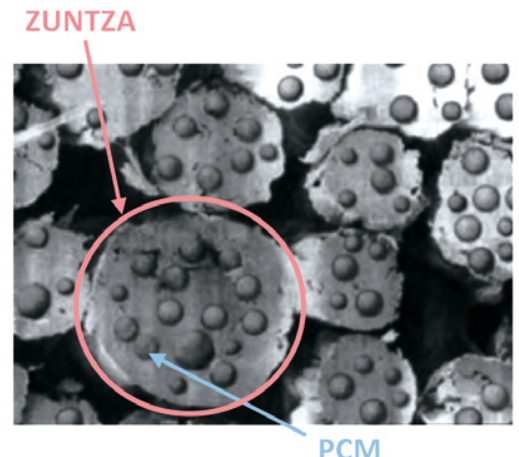

b)

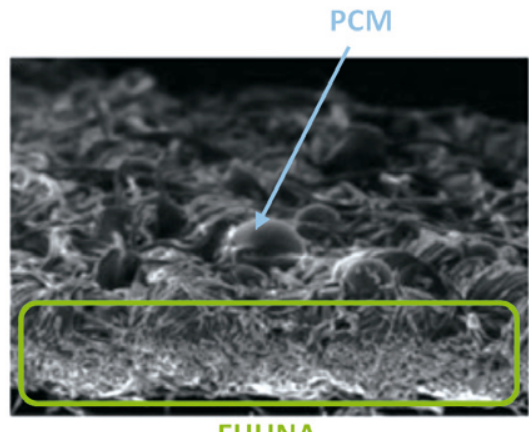

EHUNA

4. irudia. SEM irudi mikroskopikoak non mikrokapsulatutako PCMak a) zuntzekin eta b) ehunekin akoplatuta dauden [11]. 


\subsection{Aplikazioak}

SMPUek deformatzeko duten gaitasuna kontuan izanda, sektore desberdinetan erabiltzeko material ezin hobea kontsidera daiteke; hala nola, biomedikuntzan, automobilgintzan, industria aeroespazialean, eta abar [12]. Ehungintzan erabili ahal izateko, hari edo zuntz bilakatu behar dira beren propietate mekanikoak zein termikoak mantenduz. Gehienbat PU termoplastikoa erabiltzen da askatasunez mugitzeko aukera eskaintzen diotelako eramaileari, azalarekiko kontaktu atsegina duen bitartean.

Orain arte, kirol-arropetan, bainujantzietan eta jantzi babesleetan agertu izan dira gehienbat, hauen funtzionaltasun eta etekina oso ona izanik. Bainujantziei erreparatuz, 2008. urtean Speedo markak Fastskin LZR Racer® bainujantzia (5. irudia) diseinatu zuen NASAren laguntzarekin [13]. Geruza desberdinez osatuta zegoen, barne geruza nylonak (hexametilendiamina eta azido adipikoaren arteko nahasketa) eta PUak (etilenglikola eta MDI arteko nahasketa) osatzen zuten eta kanpoko geruza PUz bakarrik eginda zegoen; azken hau hidrofobikoa izanda flotatzeko gaitasuna handitzen zuen. Gainera, ohiko bainujantziekin alderatuz \% 24ko marruskadura murrizten zuen ura eta jantziaren artean eta konpresioa \% 15ean handitzen zen, mugimenduaren eraginkortasuna handiagoa izanik. Horrek Michael Phelps igerilariari abantaila eman zion urrezko 8 domina irabazteko; baina polemika handia egon zen, dopin teknologikoaren presentzia zegoela arrazoituz. Ondorioz, 2009an Igeriketako Nazioarteko Federazioa (FINA) gorputz osoko PUzko bainujantziak debekatu zituen lehiaketetan [13, 14].

a)

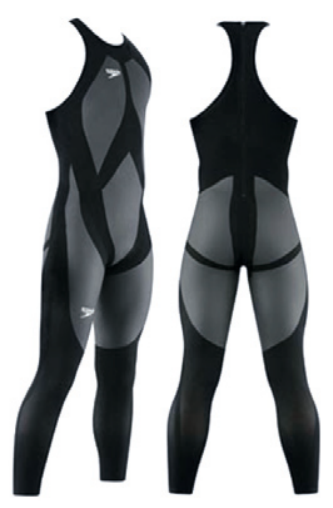

b)

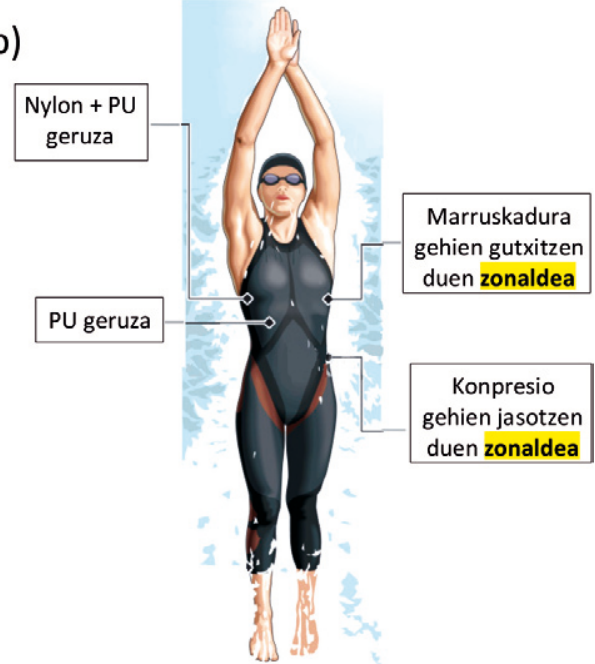

5. irudia. a) Speedo®-k diseinatutako PUzko bainujantziak eta b) funtsezko zonaldeak [13]. 
Material adimentsu moduan badira zenbait patente; hauen artean Diaplex ${ }^{\circledR}$, zeina kirol-arropetan oso erabilia den gaur egun (6a. irudia). Diaplex ${ }^{\circledR}$, SMP Technologies industrian garatzen da, Japonian [15]. Erantzuteko gaitasuna du trantsizio tenperatura (edo $\mathrm{T}_{\mathrm{g}}$ ) zehatz batean, normalean gorputz-tenperaturatik gertu aurkitzen dena. Kasu honetan, 31-33 ${ }^{\circ} \mathrm{C}$-ra heltzean, forma-memoriadun izaera dela eta, egitura molekularrean bibrazio termikoa gertatzen da mikroporoen tamaina aldatuz eta materialaren iragazkortasuna aldakor bilakatuz [16]. Modu horretan, $\mathrm{T}_{\mathrm{g}}$ baliotik behera polimero kateak zurrun egongo dira denboraldiko forma nagusitzen baita, ur molekulen iragazkortasun baxua mantenduz. Aldiz, tenperatura igotzean $\mathrm{T}_{\mathrm{g}}$-tik gora, bai inguruko tenperaturen igoeragatik, bai eramailea kirola egiten ari delako, polimero-kateen artean hutsuneak sortuko dira, ur molekulen iragazkortasuna handitzen delarik; kasu honetan, forma iraunkorra erantzule izanik. Horrela, izerdia kanpora daiteke gorputz tenperatura erosoa mantenduz (6b. irudia).

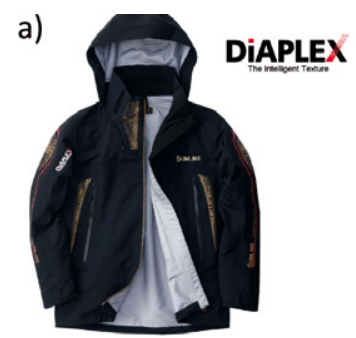

b)

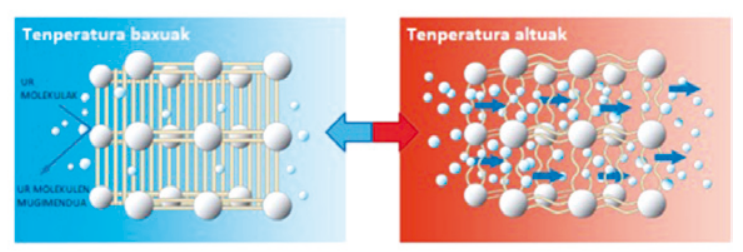

6. irudia. a) Diaplex ${ }^{\circledR}$ erabiltzen duten arropak eta b) SMPUek orokorrean duten jokaera. Tenperatura baxuetan poro tamaina txikia izango da baina tenperatura igo ahala hauek handituko dira ur-lurruna edo izerdia pasatzen utziz $[15,16]$.

Bestalde, jantzi babesleen helburua oinarritzen da gehienbat konfort termikoan. Astronauten jantzietarako (7a. irudia), NASAk PCM teknologian oinarritu da; haren funtsa termorregulazio aktiboa baita. Horrela, espazioan dagoen diferentzia termiko ikaragarria eguzki izpien eta ilargiaren itzala dela eta, astronautek oszilazio termikoetatik babes daitezke.

2003. urtean, Outlast Technologies LLC konpainiak (USA) eta NASAk Outlast ${ }^{\circledR}$ izeneko PCMa garatu zuten [17]. Material hau, zuntz akrilikoz osatuta dago eta parafinaz mikrokapsulatuta; horrela, gorputzarekin kontaktuan jartzean (tenperatura altuetan), parafina urtzen da, beroa xurgatzeko eta biltegiratzeko gaitasuna handituz. Aldiz, ingurune hotz batean, fase solidoan egongo da eta biltegiratutako beroa askatuko du gorputz tenperatura orekatzeko eta erosotasuna bermatzeko (7b. irudia). Gainera, material honek, $8{ }^{\circ} \mathrm{C}$-ko oszilazio maximoa aurkezten du [17]; beraz, konfort termikoa nabaria izango da. Gaur egun, Outlast ${ }^{\circledR}$, PCMen aitzindaria kon- 
tsideratzen da eta sektore desberdinetan erabiltzen da. Patentatutako beste PCMak dira, Thermabsorb, ConforTemp, Interactive, eta abar [11].

a)

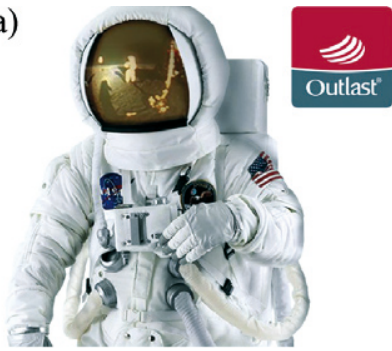

b)

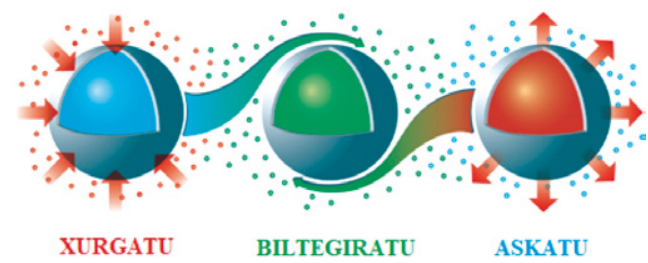

7. irudia. a) Outlast ${ }^{\circledR}$-eko astronauta jantzia eta b) PCMaren jokaera baldintzen arabera. Geziek bero norabidea azaltzen dute; barrurantz beroa xurgatzen da, kanporantz askatu eta tartean biltegiratzeko gaitasuna daukate $[17,18]$.

Beraz, aztertutako SMPUak interes handikoak direla ehungintzan ikusi da, baldin eta beren beira-trantsizioko tenperatura gorputz tenperaturatik gertu badago. Hala ere, intentsitate handiko jardueren ondorioz, edota ingurumen baldintzak direla eta, tenperatura hori altuagoa izango da. Hori dela eta, material hauek tenperatura aldaketen aurrean eraginkortasunez erantzun dezaten, forma-memoriadun poliuretano hauen trantsizio tenperatura $40-50{ }^{\circ} \mathrm{C}$-an egotea komeni da. Gainera, PCM materialak gehituz gero, arropa eramaileak oreka termikoa mantenduko du.

\section{PROZEDURA ESPERIMENTALA}

Atal honetan azaltzen da SMPUak lortzeko burutu beharreko sintesiprozesua eta horretarako zer erreaktibo erabiliko diren; baita filmak, hariak eta ehunak lortzeko jarraitutako pausoak ere.

\subsection{Erreaktiboak}

Poliuretanoaren sintesia burutzeko, erabilitako hiru erreaktibo (poliola, diisozianatoa eta kate hedatzailea) Sigma-Aldrichen erosiak izan dira. Poliol bezala, politetrametilenglikola (PTMG) erabili da bi pisu molekular desberdinekin; $650 \mathrm{~g} / \mathrm{mol}$ (PTMG 650) eta $1.000 \mathrm{~g} / \mathrm{mol}$ (PTMG 1000). Diisozianato moduan, 2,4-tolueno diisozianatoa (TDI) erabili da, pisu molekularra $174,2 \mathrm{~g} / \mathrm{mol}$ eta dentsitatea $1,22 \mathrm{~g} / \mathrm{mL}$ dituena. Azkenik, kate-hedatzaile gisa, 1,4-butanodiol (BD), 90,1 g/mol pisu molekular eta $1,017 \mathrm{~g} / \mathrm{mL}$ dentsitatearekin. 
PCM moduan Micronal ${ }^{\circledR}$ organikoa (parafinaz mikrokapsulatuta; $\mathrm{T}_{\mathrm{f}}=23{ }^{\circ} \mathrm{C}$ ) eta hexadekano ez-organikoa (silizez mikrokapsulatua; $\mathrm{T}_{\mathrm{f}}=17,7^{\circ} \mathrm{C}$ ) erabili dira, IK-4 TEKNIKER zentro teknologikotik eskuratuak.

\subsection{Sintesia}

Poliuretanoen sintesian jarraitzen den estekiometria orokorra poliol: diisozianato: kate-hedatzailea da; 1: $\mathrm{N}+1$ : $\mathrm{N}$ izanik. Kasu honetan $\mathbf{N}$ balioak ezagunak ziren, aurreko lan batean aztertu baitziren [19]: PTMG 650-TDI-BD N3 eta PTMG 1000-TDI-BD N5; non N erreaktiboen mol-ratioa adierazten duen eta kasu bietan, diisozianato eta poliol erlazioa $\mathrm{NCO} /$ $\mathrm{OH}=1$ izanik, emaitza oso onak eskuratu ziren.<smiles>Cc1ccc(N=O)cc1[N+](=O)[O-]</smiles>

$80^{\circ} \mathrm{C}$
$2 \mathrm{~h}$<smiles>CC(=O)Nc1cc(NC(=O)CCCCOC(C)(C)C)ccc1C</smiles>

AURREPOLIMEROA<smiles>[B]CCCCO</smiles>

$3 \min$<smiles>Cc1ccc(NC(=O)C(C)(C)C(=O)Nc2ccc(C)c(NC(=O)OCCCCOC(C)(C)C)c2)cc1NC(=O)OCCCCOC(C)(C)C</smiles>

SMPU

8. irudia. SMPUren sintesi prozesuaren eskema.

Sintesi prozesuan bi etapa bereizten dira (8. irudia); lehenengoan, aurrepolimeroaren sintesia burutzen da, poliol (PTMG 650 edo PTMG 1000) 
eta diisozianato (TDI) bidezko nahasketatik lortutakoa. Erreaktiboak bi orduz erreakzionatzen uzten dira $80{ }^{\circ} \mathrm{C}$-an $150 \mathrm{~mL}$-ko bost ahoko matraze borobil batean, irabiagailu mekaniko $(250 \mathrm{rpm})$ eta nitrogeno sarrera batekin ekipatuta. Nitrogeno fluxua erabiltzen da isozianato eta airearen arteko albo-erreakzioa ekiditeko. Bigarren urratsean, kate hedatzailea (BD) gehitzen da, aurretik 3 orduz $65{ }^{\circ} \mathrm{C}$-ra lehortzen egon dena, eta nahasten da 3 minutuz, likatasunaren handitzea nabarmendu arte; hau da, PTMG 650TDI-BD N3 eta PTMG 1000-TDI-BD N5 lortu arte.

\subsection{Filmak, hariak eta ehunak egiteko prozesua}

Filmak egiteko (9a. irudia), sintesia burutu bezain laster, nahastea hoztu eta gogortu baino lehen $0,26 \mathrm{~mm}$-ko molde lau baten gainean $3 \mathrm{~g}$ inguru botatzen dira, eta plaka metalikoen artean jartzen dira, non tefloi filmak bi aldeetan dauden, gainazaleko zimurtasuna txikitzeko asmoz eta ez itsasteko. Jarraian, prentsa hidraulikora sartzen da 24 orduz, $120^{\circ} \mathrm{C}$-an eta 150 bar-ean.

Harien kasuan (9b. irudia), sintesia bukatu bezain laster, silikonazko moldeen gainean ipini eta muflan sartzen da $100{ }^{\circ} \mathrm{C}$-an, 20 orduz eta presiorik gabe. Hariak egiteko, Thermo-scientific-Haake-minilab II estrusiomakinan sartzen da lagina, pikor moduan eta presiopean. Berotzen hasten da $175-180{ }^{\circ} \mathrm{C}$-ra arte eta torloju-birakariari esker, homogeneoki nahasten da; amaieran burutik ateratzen delarik zehaztutako diametroarekin; kasu honetan, 0,5 mm dena. Hozten da eta bobina batean biltzen da haria.

PCM materialen kasuan, estrusio-prozesuan bertan kargatzen dira PU laginetan. Modu horretan, Micronal ${ }^{\circledR}$ organikoz eta hexadekano ez-organikoz kargatutako hariak lortuko dira bi SMPU desberdinetan.

Hariak behin izanda, puntu-ehunak egiteko (9c. irudia), LK-150 makina erabiltzen da. PUzko hariak erabili aurretik, kotoizko haria erabili da hasiera egiteko, gero neurketak egiteko orduan, euste puntu hobeagoa izateko; eta amaieran, kakorratz-lana burutu da haria ez askatzeko. Tartean, SMPUekin trikotatzen da.

a)

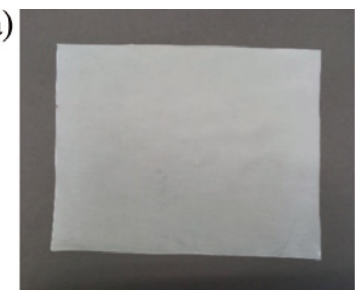

b)

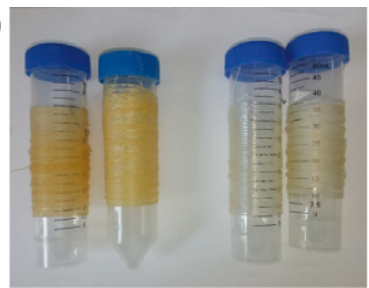

c)

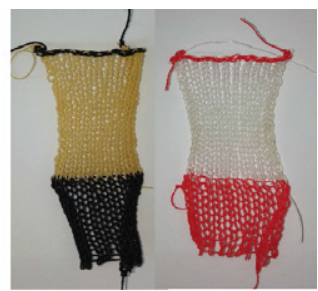

9. irudia. Sintetizatutako PTMG 1000-TDI-BD N5 a) film moduan, b) hariak Falcon hodietan kiribilduta eta c) puntu-ehunak; ezkerrean kargatuta Micronal@arekin eta eskuinean kargatu gabe. 


\subsection{Karakterizazio teknikak}

\subsubsection{Azterketa dinamiko-mekanikoa}

Azterketa dinamiko-mekanikoan (Dynamic-mechanical analysis, $D M A$ ), lagina esfortzu sinusoidal periodiko baten aurrean jartzen da, berotzen den bitartean, materialak duen erantzuna deformazio modu desberdinen aurrean aztertzeko [20]. Modu horretan, polimeroaren biltegiratze modulua $\left(\mathrm{E}^{\prime}\right)$, galtze modulua $\left(\mathrm{E}^{\prime \prime}\right)$ eta galtze faktorea $(\tan \delta)$ determina daitezke. Biltegiratze moduluari dagokionez, materiala deformatzean biltegiratzen duen energia elastikoa kuantifikatzen du eta modu horretan, materialak duen zurruntasuna determina daiteke. Galtze moduluaren kasuan, galdutako energia neurtzen du bero gisa. Bi moduluen arteko erlazioa $\tan \delta=E^{\prime \prime} / E^{\prime}$ osatzen dute, zeinak $T_{g}$ balioa zehazten duen eta gailurraren maximoan aurkitzen den.

Esperimentua aurrera eraman da DMA-1 Mettler Toledo ekipoarekin, $1 \mathrm{~Hz}$-ko frekuentzian eta $20 \mu \mathrm{m}$-ko desplazamenduarekin. Laginak $-100{ }^{\circ} \mathrm{C}$ tik $150{ }^{\circ} \mathrm{C}$-rainoko lan tartean aztertu dira, $3{ }^{\circ} \mathrm{C} / \mathrm{min}$-ko berotze abiadurarekin.

\subsubsection{Azterketa termomekanikoa}

Azterketa termomekanikoa (Thermo-mechanical analysis, TMA) poliuretanoen forma-memoria aztertzeko erabiltzen da. Horretarako, DMAtik lortutako $\mathrm{T}_{\mathrm{g}}$ balioaren gainetik eta azpitik lan egin behar da; ekipoa aurreko berdina izanik, DMA-1 Mettler Toledo.

Lehenik eta behin, lagina $100{ }^{\circ} \mathrm{C}$-raino berotzen da ( $\mathrm{T}_{\mathrm{g}}$ gainetik). Jarraian, $2 \mathrm{~N}$-ko indarra aplikatzen da, laginaren gehienezko luzapena $\left(D_{\max }\right)$ lortu arte. Ondoren, hozten da $100{ }^{\circ} \mathrm{C}$-tik $-50{ }^{\circ} \mathrm{C}$-ra ( $\mathrm{T}_{\mathrm{g}}$ azpitik) $20^{\circ} \mathrm{C} / \mathrm{min}$ abiadurarekin, eta konstante mantentzen da 30 minutuz denboraldiko forma finkatuz $\left(D_{F}=0\right)$. Prozesu honen ostean, indarra deuseztatzen da $(\mathrm{F}=0 \mathrm{~N})$ eta 5 minutuz mantentzen dira baldintza horietan. Azkenik, lagina berriro berotzen da $-50{ }^{\circ} \mathrm{C}$-tik $100{ }^{\circ} \mathrm{C}$-raino, forma iraunkorra berreskuratzeko memoria-efektua aktibatzean $\left(D_{F}\right)$.

Teknika honen bitartez, laginak jasandako deformazioa, finkapena eta berreskurapena ehunekotan kalkula daitezke hurrengo ekuazioen bidez (1-3):

$$
\begin{gathered}
\text { \% Deformazioa }\left(R_{d}\right)=\left(\frac{D_{\max }}{L}\right) \cdot 100 \\
\text { \% Finkapena }\left(R_{f}\right)=\left(\frac{D_{F=0}}{D_{\max }}\right) \cdot 100 \\
\text { \% Berreskurapena }\left(R_{r}\right)=\left(\frac{D_{\max }-D_{F}}{D_{\max }}\right) \cdot 100
\end{gathered}
$$




\subsubsection{Trakzioa}

Trakzioa, lagin bati indar uniaxiala aplikatzen zaionean laga egin edo apurtu arte; modu horretan laginak duen portaera eta propietate mekanikoak analiza daitezke [21].

Esperimentua aurrera eraman da Shimadzu Autograph makinaren bitartez, $500 \mathrm{~N}$-eko karga zelula erabilita eta luzapen abiadura $20 \mathrm{~mm} / \mathrm{min}$ aplikatuz. Erabilitako laginak eta hauen parametroak izan dira: $0,5 \times 10 \times 0,5 \mathrm{~mm}^{3}$ (lodiera $\times$ luzera $\times$ zabalera) harientzako eta $2 \times 15 \times 40 \mathrm{~mm}^{3}$ ehunentzako. Inguruko tenperaturan burutu da esperimentua eta neurtutako parametroak izan dira: Young modulua (E), esfortzua eta deformazioaren arteko erlazioa dena; isurpenarekiko erresistentzia eta deformazioa $\left(\sigma_{\mathrm{y}}\right.$ eta $\left.\varepsilon_{\mathrm{y}}\right)$, materialak deformazio plastikoa gertatzeari egiten dion erresistentzia eta deformazioa (\% 0,2-ko luzeran); eta haustura tentsioa eta deformazioa $\left(\sigma_{\mathrm{b}}\right.$ eta $\left.\varepsilon_{\mathrm{b}}\right)$, laginaren apurketa gertatzen deneko puntua, non aplikatutako erresistentzia eta zeukan luzera adierazten duten.

\subsubsection{Gas iragazkortasuna}

Edozein gasen iragazkortasuna neurtzeko, kontuan hartu beharra dago ur-lurruna transmititzeko indizea (Water Vapour Transmission Rate, $W V T R$ ) (4. ekuazioa) polimeroan zehar [22].

$$
W V T R=\frac{w \cdot x}{A \cdot t \cdot\left(p_{2}-p_{1}\right)}\left[\frac{g \cdot m m}{m^{2} \cdot e g u n}\right]
$$

$w$ irabazitako pisua, $\mathrm{x}$ filmaren lodiera, $A$ tapoian ikusgai dagoen filmaren azalera, $\mathrm{t}$ esperimentuaren denbora eta $p_{2}-p_{1}$ filmen arteko ur lurrunaren presio diferentzia izanik.

Esperimentu hau burutzeko, beirazko saiodiak erabili dira, non $25 \mathrm{~g}$ silika-gela sartu diren bakoitzean. Hauen estalkietan, azalera zehatzeko zulo bat izanik $\left(9,62 \mathrm{~cm}^{2}\right)$; SMPUzko filmak saio-hodiaren eta tapoiaren artean kokatzen dira eta behartutako inguruneko baldintza batzuen aurrean jarriz filmek duten portaera aztertzen da. Baldintza horiek labe batean ematen dira, non $\% 95$ eko hezetasuna dagoen eta tenperatura $20^{\circ} \mathrm{C}$-tik $80{ }^{\circ} \mathrm{C}$-ra igotzen den; hau da, SMPU guztien $\mathrm{T}_{\mathrm{g}}$-ren azpitik eta gainetik.

\section{EMAITZAK ETA EZTABAIDA}

\subsection{Azterketa dinamiko-mekanikoa}

Teknika dinamiko honi esker sintetizatutako SMPUen $\mathrm{T}_{\mathrm{g}}$-ak determinatu dira, eta PTMG 650-TDI-BD N3rena (10a. irudia) PTMG 1000TDI-BD N5ena (10b. irudia) baino baxuagoa izan da. Efektu hau katearen 
malgutasunaren ondorio da; zenbat eta poliolaren pisu molekularra handiagoa izan, are malgutasun gutxiago; ondorioz, $\mathrm{T}_{\mathrm{g}}$ handitzen da. Baina $\mathrm{N}$ balioak eragina izan dezake ere, eta hau handitu ahala $\mathrm{T}_{\mathrm{g}}$ handitzen da; izan ere, baieztapen hau beste lanean frogatua izan da [19]. Bestalde, PCMak gehitzean aurkeztu duten joera orokorra izan da $T_{\mathrm{g}}$-ren murrizpena, biek dutelako efektu plastifikatzailea polimeroarengan. Ez-organikoaren kasuan balioak baxuagoak dira; fasez aldatzeko tenperatura kargatu gabe dagoena baino baxuagoa delako; edota Micronal ${ }^{\circledR}$ organikoak zati kristalinoa duenez gero, beltzez adierazita dauden PUak baino $\mathrm{T}_{\mathrm{g}}$ baxuagoa ikusten da kasu bietan. Hau kontuan izanda, konposatu kargadunen zurruntasuna zehaztu daiteke biltegiratze moduluan oinarrituz (10c. irudia). Kasu honetan, PTMG 650-TDI-BD N3 konposatu kargadunek energia antzeko moduan biltegiratzeko gai dira; hau da, elastikotasun maila parekoa aurkezten dute. PTMG 1000-TDI-BD N5 konposatu kargadunen kasuan, joera desberdina ikusten da. Hexadekanoak SMPUari efektu elastikoagoa eskaintzen dion bitartean; Micronal ${ }^{\circledR}$-ak SMPU zurrunena erakusten du, eta zentzuzkoa kontsidera daiteke aurreko ondorioak aintzat hartuta. Azkenik, gailurren lodierari erreparatuz, PTMG 1000n oinarritutako SMPUak zabalagoak direnez, polidispertsoagoak dira.

a)

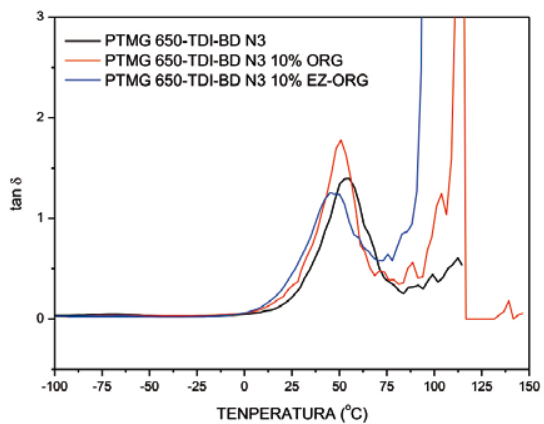

b)

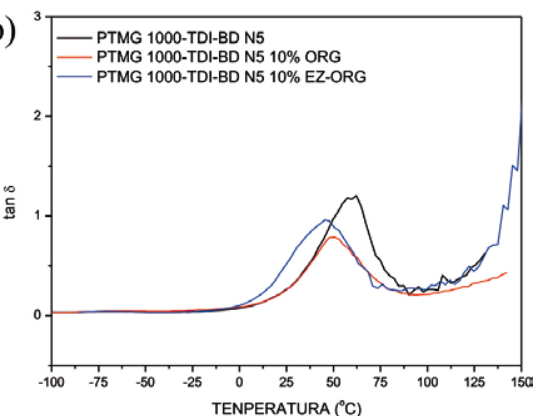

c)

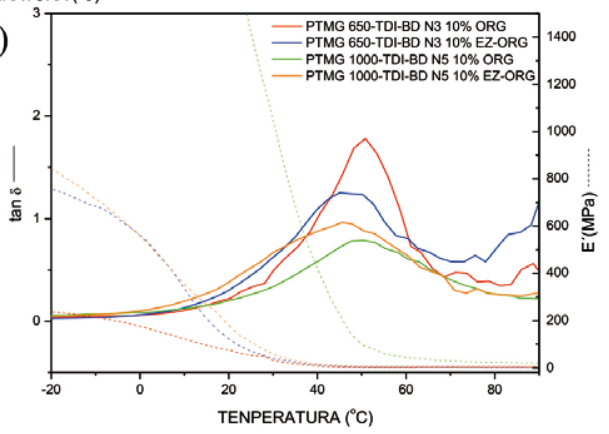

10. irudia. Sintetizatutako SMPUen DMA termogramak, $T_{g}$ gailurra izanik; a) PTMG 650ean eta b) PTMG 1000n oinarritutakoak. c) Kargatutako harien biltegiratze modulua. 


\subsection{Azterketa termomekanikoa}

SMPUen forma-memoria kuantifikatzeko, TMA teknika erabili da. 11. irudian emaitzak ikusten dira. Deformazioaren aldetik $\left(\% \mathrm{R}_{\mathrm{d}}\right)$, berdina da SMPU guztientzat; non \% 5ekoa onargarria kontsidera daitekeen ehunen aplikaziorako. Berreskurapen-faktoreak ikusita $\left(\% \mathrm{R}_{\mathrm{r}}\right)$, sintetizatutako SMPUek ez dute hasierako forma bere osotasunean berreskuratzen, \% 6476ko tartea bueltatzen baita. PCMz kargatzean, argi ikus daiteke, organikoak duen zati kristalinoa dela eta, deformazio gaitasuna txikiagoa dela. Azkenik, finkapen balioei erreparatuz $\left(\% \mathrm{R}_{\mathrm{f}}\right)$, guztiak \% 96-98 tartean daude. Beraz, forma-memoriaren erantzuleak dira guztiak.

a)

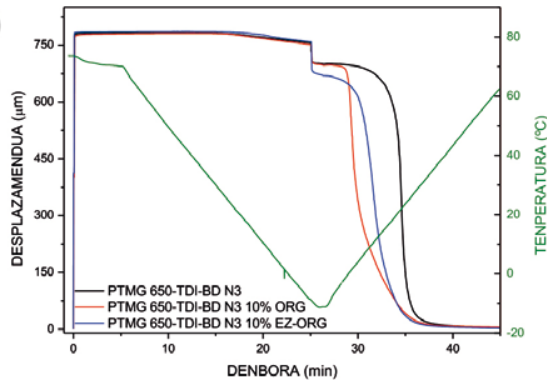

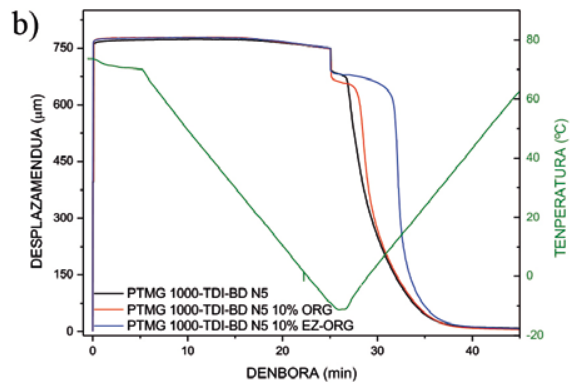

11. irudia. Sintetizatutako SMPUen TMA diagramak: a) PTMG 650ean eta b) PTMG 1000n oinarritutakoak.

\subsection{Trakzioa}

SMPU harien eta ehunen trakzioa aztertu da, eta orokorrean izaera elastomerikoa erakusten dute hasieran, gero efektu plastikoa agertzen da elongazioa handitu ahala. Lortutako emaitza guztiak 1. taulan laburbiltzen dira.

Harien kasuan (12. irudia), PTMG 650-TDI-BD N3k hausturarekiko deformazio handiena erakusten du (\% 1557). Lagin hau kargatzean, propietate aldaketak nabariak dira eta lehenago apurtzen dira, aurretik aipatu den moduan efektu plastifikatzailearen ondorioa. PTMG 1000-TDI-BD N5en kasuan, haustura puntua lehenago gertatzen da (\% 507); segmentu gogorraren tamaina handitzeak material zurrunago, edo berdina dena, apurkorragoa bilakatzen duelako. Gainera, efektu hau begi-bistaz ere bereizi da, PTMG 1000-TDI-BD N5 hariak barne-pitzadurak aurkeztu dituelako. Orokorrean, PCMak gehitzean, alde batetik Micronal ${ }^{\circledR}$ organikoa duen lagina lehenago apurtu da, aurretik aipatutako arrazoiagatik: zati kristalinoa. Beste aldetik, ez-organikoaren kasuan, portaera nahiko desberdina izan du PTMG 650 eta PTMG 1000ren artean; bai erresistentziaren aldetik, bai deformazioaren aldetik. Kasu honetan hariaren forma izan da emaitza hauen erantzulea, partikula ez-organikoak gehitzean elastikoagoa bilakatzeaz gain, estrusio 
bidez lortutako haria hain mehea izan da, kasu batzuetan lehenago edo beranduago apurtzea ere eragin duela.
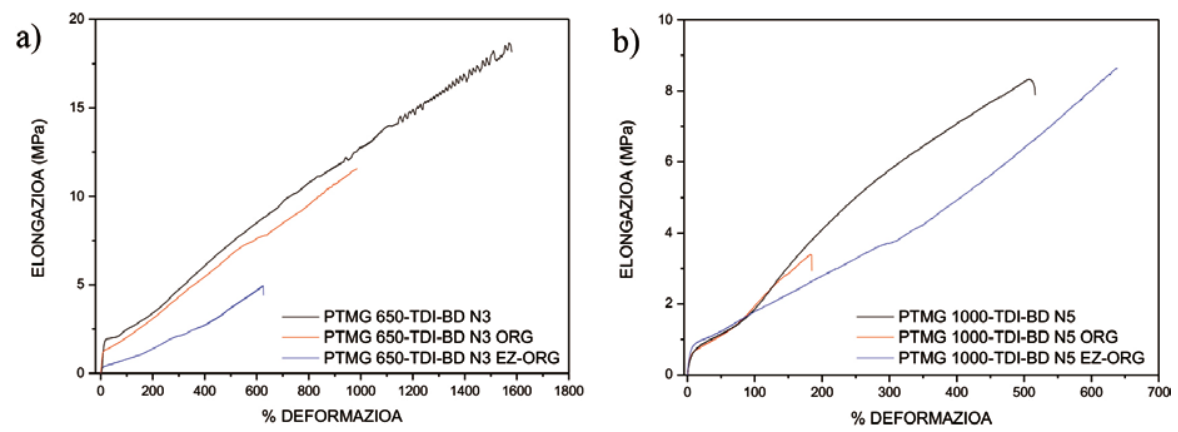

12. irudia. Harien tentsio-deformazio diagramak: a) PTMG 650ean eta b) PTMG 1000n oinarritutako SMPUak.

Ehunen kasuan, hariek aurkezten duten portaera antzekoa da. Hala ere, ehunak hariak baino tentsio handiagoa jasan dezake orokorrean eta, era berean, elastikoagoak dira; horregatik, ehungintzarako material ezin hobea kontsidera daiteke. Emaitzak ikusita, PTMG 650-TDI-BD N3ren balioa \% 1343 da; hariarena baino baxuagoa izan arren, deformazio handia daukate biek; beraz, aproposa da lan honen helbururako. PTMG 1000-TDI-BD N5ekin \% 976 deformazioa lortu da, hariarekiko desberdintasun nabarmenagoa izanik. Hala ere, esan beharra dago lortutako balioak oso altuak direla.
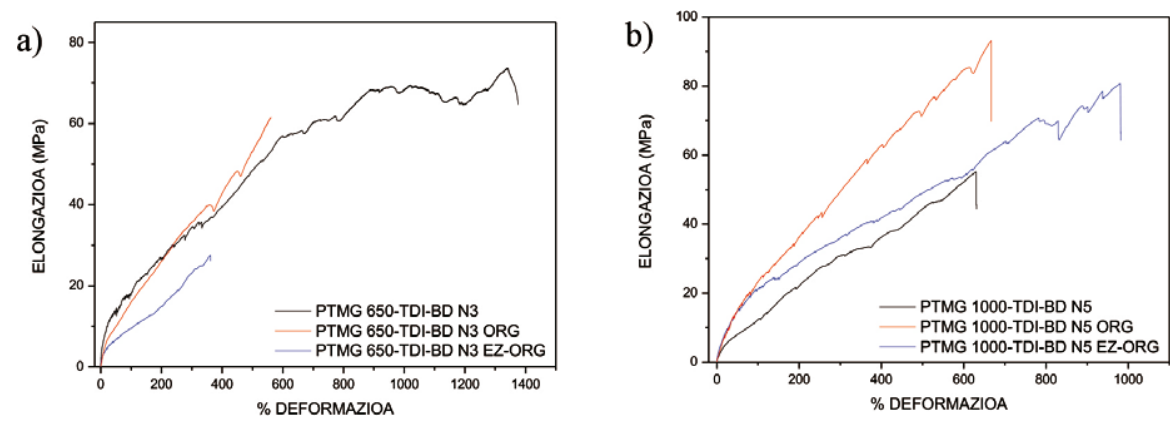

13. irudia. Ehunen tentsio-deformazio diagramak: a) PTMG 650ean eta b) PTMG 1000n oinarritutako SMPUak

14. irudian, ikus daiteke nola ehun bati tentsioa aplikatzen ari zaion, ehuna apurtu arte. Modu horretan, 13. irudiko diagramak eskuratzen dira, zeinetan hainbat gailur beherantz bereizten diren. Bi arrazoi izan daitezke malda aldaketaren erantzuleak. Alde batetik, polimero nahastea denez, 
gerta daiteke barne loturak apurtzea edo/eta desplazatzea, tentsioan eragina izanik; hau da, mikroegituraren menpekoa da. Beste aldetik, ehuna hainbat kiribilez osatuta dagoenez, ez dute era berean tentsioa jasaten, eta gerta daiteke hariaren zati bat apurtzea baina ehunak tentsioa oraindik jasatea.

a)

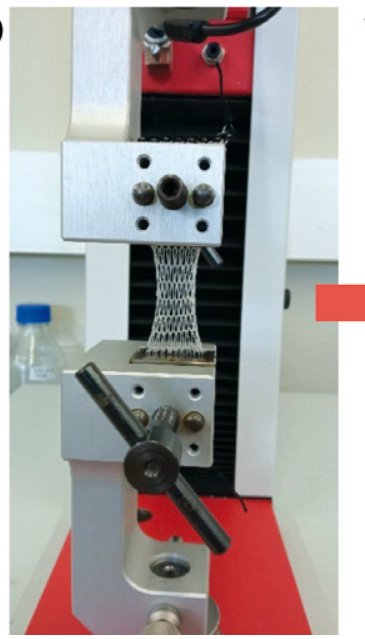

b)

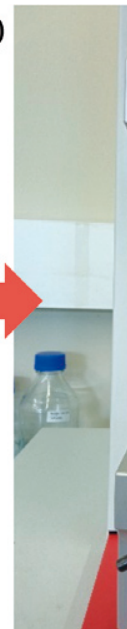

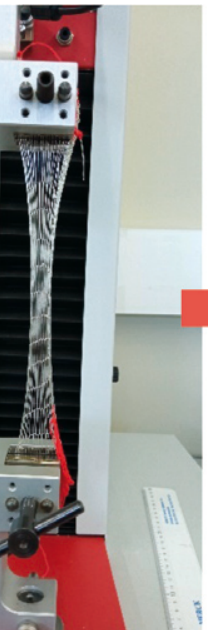

c)

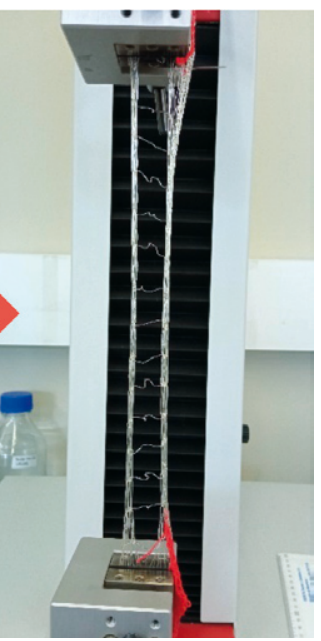

14. irudia. Ehunen portaera trakzioarekiko erresistentzia aplikatzearen argazkiak. Tentsio desberdina aplikatzerakoan PTMG 1000-TDI-BD N5 laginean. a) Tentsiorik gabe, b) tentsioa aplikatzean eta c) tentsioa mugara heltzean ehuna apurtuz.

1. taula. Sintetizatutako SMPU harien eta ehunen trakzio parametroak.

\begin{tabular}{|c|c|c|c|c|c|c|}
\hline & SMPU & $\mathrm{E}(\mathrm{MPa})$ & $\sigma_{\mathrm{y}}(\mathrm{MPa})$ & $\% \varepsilon_{\mathrm{y}}$ & $\sigma_{\mathrm{b}}(\mathrm{MPa})$ & $\% \varepsilon_{\mathrm{b}}$ \\
\hline \multirow{6}{*}{ 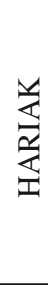 } & PTMG 650-TDI-BD N3 & $1,25 \pm 0,02$ & 1,9 & 17,7 & 18,4 & 1558 \\
\hline & $+\% 10 \mathrm{wt}$ ez-org & $0,93 \pm 0,04$ & 0,3 & 4,3 & 4,9 & 616 \\
\hline & $+\% 10 \mathrm{wt}$ org & $1,36 \pm 0,02$ & 1,2 & 10,3 & 11,3 & 959 \\
\hline & PTMG 1000-TDI-BD N5 & $0,73 \pm 0,01$ & 0,7 & 10,4 & 8,3 & 508 \\
\hline & $+\% 10 \mathrm{wt} \mathrm{ez-org}$ & $0,89 \pm 0,02$ & 0,9 & 10,1 & 8,6 & 636 \\
\hline & $+\% 10 \mathrm{wt}$ org & $0,83 \pm 0,02$ & 0,7 & 9,1 & 3,4 & 183 \\
\hline \multirow{6}{*}{ 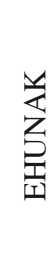 } & PTMG 650-TDI-BD N3 & $4,20 \pm 0,10$ & 3,7 & 2,1 & 73,1 & 1343 \\
\hline & $+\% 10 \mathrm{wt} \mathrm{ez-org}$ & $1,76 \pm 0,03$ & 2,9 & 6,5 & 27,2 & 356 \\
\hline & $+\% 10$ wt org & $1,57 \pm 0,01$ & 6,5 & 20,4 & 60,5 & 552 \\
\hline & PTMG 1000-TDI-BD N5 & $4,64 \pm 0,12$ & 4,7 & 18,3 & 80,5 & 976 \\
\hline & $+\% 10 \mathrm{wt} \mathrm{ez-org}$ & $2,45 \pm 0,02$ & 9,2 & 23,2 & 92,6 & 663 \\
\hline & $+\% 10 \mathrm{wt}$ org & $1,64 \pm 0,03$ & 12,7 & 39,9 & 54,8 & 629 \\
\hline
\end{tabular}




\subsection{Gas iragazkortasuna}

Ur lurrunaren iragazkortasuna PTMG 650-TDI-BD N3 eta PTMG 1000-TDI-BD N5 SMPUetan aztertu da, bakoitzetik hiru lagin. WVTR kalkulatzeko, kristalezko saio-hodiak silika-gelarekin pisatu dira, eta egun desberdinetan pisaketak egin dira (inguruneko tenperaturan) ur-lurrunaren iragazkortasuna aztertzeko; modu horretan eta 4. ekuazioaz baliatuz, 15. irudia lortu da. Jakinda filmaren porotasunaren menpekoa dela, argi ikus daiteke nola, tenperatura handitu ahala, poroen tamaina handitzen den eta ur-lurrunak errazago filma gurutzatzen duen. Hasieran eta $20^{\circ} \mathrm{C}$-an gas gehiago pasa da; baldintza horietan jarri baino lehen lehorgailuan egon baitira filmak. Gero, espero den joera antzematen da, $70{ }^{\circ} \mathrm{C}$-ra heldu arte; non PTMG 1000ko filmean likatasuna handitzen hasi den; horren ondorioz poroak estutu dira gasaren iragazkortasuna zailduz. Amaieran, kasu gehienetan silika-gelak kolorez aldatu da; beraz, esan daiteke aseta dagoela $80{ }^{\circ} \mathrm{C}$-an eta ondorioz amaieran ez da gorakada hain nabarmena antzematen. Bestalde, $40-50{ }^{\circ} \mathrm{C}$ tartean oinarrituz, non SMPUen $\mathrm{T}_{\mathrm{g}}$ aurkitzen den, malda aldaketa nabarmena da; beraz, ehungintzan erabiliz gero, bere helburua beteko luke.

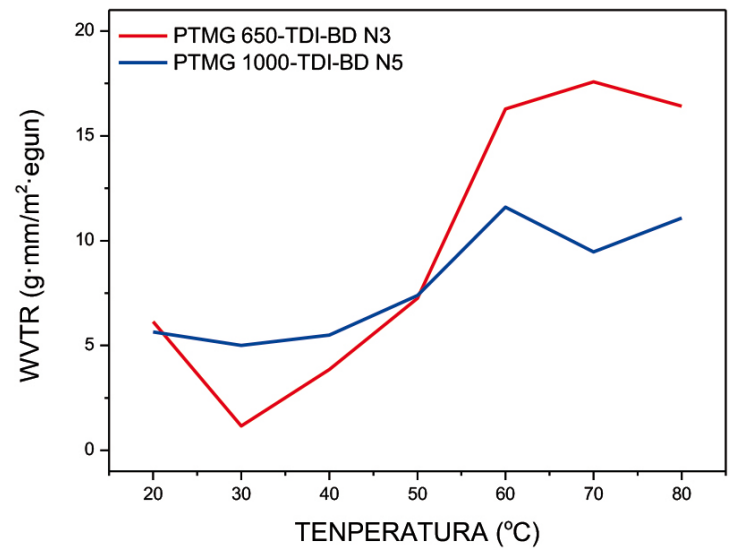

15. irudia. Sintetizatutako SMPUen eta komertzialaren WVTR tenperaturaren menpe.

\section{ONDORIOAK}

Ikerketa honetan, PTMG 650-TDI-BD N3 eta PTMG 1000-TDI-BD N5 sintetizatu dira, non hariak eta ehunak garatzea lortu den eta haien propietate mekaniko, termiko zein fisiko-kimikoak analizatu diren; baita filmen gas iragazkortasuna ere; horrela, ehungintzarako baliozkoak diren edo 
ez determinatzeko. Gainera, PCM materialak gaineratu zaizkie, konposatu mota hauek eman ditzaketen abantailak ehunetan aplikagarriak diren edo ez ikusteko.

Orokorrean, $T_{g}$ espero dena baino altuagoa lortu da; izan ere, hariak egiteko berotze-prozesu bat jasan behar izan dute SMPUek; estrusio-prozesua zehazki, eta tenperatura altuen ondorioz propietateak aldatu dira. Bestalde, PCMak $\mathrm{T}_{\mathrm{g}}$ txikitzeko joera dute efektu plastifikatzailea dela eta. Hala ere, $\mathrm{T}_{\mathrm{g}}$ hauekin kirol-arropetan erabiltzeko aukera posible izango litzateke. Gainera, forma-memoriadun izaera dutela antzeman da SMPU guztietan. Materialek erakutsi duten elongazioari dagokionez, orokorrean balio nahiko handiak erakutsi dituzte; ehunarenak hariak baino askoz handiagoak. Hala ere, Micronal ${ }^{\circledR}$ PCMak dituzten laginek, bere egitura kimikoan duten zati kristalinoa dela eta, elongazio mugatuago dute giro tenperaturan. Hexadekanoaren kasuan, emaitzak desberdinak aurkeztu ditu PTMG 650 eta PTMG 1.000ren artean. Materialari elastikotasuna eskaintzen dion arren, haria zehaztutako diametroa baino meheagoa lortu denez, eragin zuzena izan du SMPUen portaeran. Hala ere, parafina estalkia eraginkorragoa kontsidera daiteke.

Bestalde, puntu-ehunak garatu dira, hari bakarrez osatuta daudenak. Hori dela eta, hari bat apurtuz gero, ehuna erraz apur daiteke. Horregatik, interesgarria izango litzateke beste ehun motak garatzea eta aztertzea. Film moduan, ikusi da gas iragazkortasuna $\mathrm{T}_{\mathrm{g}}$ balioan eraginkorra dela; hala ere, PTMG 1000-TDI-BD N5 tenperaturarekiko nahiko sentikorra izan denez gero, PTMG 650-TDI-BD N3 ehungintzarako SMPU onena dela kontsideratu da.

\section{BIBLIOGRAFIA}

[1] Explainer: What are polymers? https://www.sciencenewsforstudents.org/ article/explainer-what-are-polymers (Sarrera 2021/06/10).

[2] Plastic materials: What is the difference between thermoplastics, thermosets and elastomers? https://ipeweb.com/thermoplastic-extrusion/plastic-materialswhat-is-the-difference-between-thermoplastics-thermosets-and-elastomers/ (Sarrea 2021/09/19).

[3] SÁez-Pérez, M.; Lizundia, E.; Laza, J.M.; García-Barrasa, J.; Vilas, J. L. 2016 «Methylene diphenyl diisocyanate (MDI) and toluene diisocyanate (TDI) based polyurethanes: thermal, shape-memory and mechanical behavior». The Royal Society of Chemistry, 6, 69094-69102.

[4] Procesos y plásticos. http://plasticosyprocesos.blogspot.com/2014/09/termoplasticos-los-termoplasticos.html (Sarrera 2021/06/12).

[5] Malmierca, M. A.; Mora-Barrantes, I.; Posadas, P.; GonZÁlez-Jiménez, A.; Marcos-Fernández, A.; Rodríguez, A.; Ibarra, L.; Valentín, J. L. 
2012 «Polímeros con memoria de forma: Un nuevo horizonte para los elastómeros». Revista de Plásticos Modernos. 104, 105-112.

[6] Sáenz-Pérez, M.; Bashir, T.; Laza, J. M.; García-Barrasa, J.; Vilas, J. L.; SKRIFVARS, M.; LEÓN, L. M. 2019 «Novel shape-memory polyurethanes fibers for textile applications». Textile Research Journal. 89, 1027-1037.

[7] Touchet, T. eta Cosgriff-Hernandez, E. 2016. Advances in Polyurethane Biomaterials. Woodhead publishing. Cambridge.

[8] CRuZ, S.M. eta ViAnA, J.C. 2015. «Melt bleding and characterization of carbon nanoparticles-filled thermoplastic polyurethane elastomers». Journal of Elastomers and Plastics. 47, 647-665.

[9] Polymer Composites Part One: Introduction. https://polymerinnovationblog. com/polymer-composites-part-one-introduction/ (Sarrera 2021/06/11).

[10] HU, H. 2020. «Recent advances of polymeric phase change composites for flexible electronics and thermal energy storage system». Composites Part B. 195, 108094.

[11] SÁNCHEZ, J.R. 2007. «Los tejidos inteligentes y el desarrollo tecnológico de la industria textil». Técnica industrial. 285, 39-45.

[12] SÁEnZ-Pérez, M. 2018 «Shape Memory Polyurethanes. Applications in smart fabrics». Doktorego-tesi lana.

[13] El poliuretano en nuestra vida: los bañadores de poliuretano. https://aislaconpoliuretano.com/el-poliuretano-en-nuestra-vida-los-banadores-de-poliuretano/ (Sarrera 2021/06/05).

[14] Chemistry of materials. Fastskin LWR Racer. http://chemistryofmaterials2013.wikidot.com/jason-nikhomvan (Sarrera 2021/06/05).

[15] Diaplex ${ }^{\circledR}$. https://www.mcf.co.jp/en/service/diaseries/diaplex.html (Sarrera 2021/04/15).

[16] Tejidos inteligentes. La tecnología detrás de las prendas. https://www.desnivel.com/material/material-noticias/tejidos-inteligentes-la-tecnologia-detrasde-las-prendas/ (Sarrera 2021/05/05).

[17] Outlast ${ }^{\circledR}$ https://www.outlast.com/es/ (Sarrera 2021/06/07).

[18] Nano PCM. http://icnqt.com/nano-products/nano-pcm/ (Sarrera 2021/06/06).

[19] Serván Herce, C.; Vilas J. L.; Veloso, A. 2019. «Síntesis de poliuretanos con memoria de forma para su aplicación en textiles». Gradu Amaierako Lana.

[20] Mettler Toledo. Analizador dinamo-mecánico (DMA) https://www.mt.com/ int/es/home/products/Laboratory_Analytics_Browse/TA_Family_Browse/ DMA.html (Sarrera 2021/05/03).

[21] QI, H. eta BoYce, M. 2005 «Stress-strain behavior of thermoplastic polyurethanes». Mechanics of Materials. 37, 817-839.

[22] Reizabal, A.; LaZA, J.M.; Cuevas, J. 2019 «PCO-LLDPE thermoresponsive shape memory blends». European Polymer Journal. 119, 469-476. 